\title{
Discurso falso y literatura en Platón. Una discusión a partir de $R$. II 376d-379a
}

\author{
CAROLina DELGado \\ Consejo Nacional de Investigaciones Científicas y Técnicas \\ Universidad Nacional de General Sarmiento \\ cdelgado@ungs.edu.ar
}

Resumen: Este trabajo intenta dilucidar el significado de la afirmación polémica de Platón relativa a la índole peculiar de los relatos literarios que, aunque falsos, encierran también algunas verdades ( $R$. II 377a6), pues resulta problemático que Platón, al mismo tiempo, critique esos relatos $y$, sin embargo, proponga también hacer uso de otros igualmente falsos. Examino tres posibilidades de desambiguar el sentido de pseûdos en estos contextos - "falso" designaría ficción o mentira verbal o el carácter de uno de los dos niveles (fáctico o normativo) que constituiría un relato literario- y defiendo que la falsedad rechazable para Platón es sólo la atinente al núcleo tipológico contenido en esos relatos.

Palabras clave: pseûdos, ficción, mentira noble, literatura

\begin{abstract}
This paper attempts to elucidate the meaning of the controversial Platonic statement in relation to the peculiarity in the literary accounts which, in spite of being false, contain at the same time certain truths ( $R$. II 377a6). Furthermore, there seems to be contradiction in the fact that Plato critiques those writings and still proposes using others equally false. I analyze three possibilities to disambiguate the meaning of pseûdos in these contexts - "false" would point to fiction or to a verbal lie or the character of one of the two levels (factual or normative) which would comprise a literary account; and I support the fact that, for Plato, the undesirable falsity is only the one related to the typological core comprised in those accounts.
\end{abstract}

Key words: pseûdos, fiction, noble lie, literature

El tema que analizo en las páginas siguientes forma parte, a decir verdad, de una problemática más amplia, a saber, la relativa a la eventual legitimación del recurso a la "mentira" que habría sido previsto por Platón para afrontar determinadas circunstancias políticas. Ya por sí sola esta problemática ha despertado, en el ámbito de los estudios platónicos, una larga polémica que ha generado una bibliografía especializada considerablemente profusa. ${ }^{1}$ Tanto por ser este tema sólo una arista de esa cuestión más abarcadora, como también por el hecho de que haya proliferado sobre el mismo una buena cantidad de estudios, creo

${ }^{1}$ Entre otros, puede mencionarse a Ferrari 2008, Schofield 2006, Calabi 1998, Gill 1993, Ashbaugh 1991, Belfiore 1985 y Battin 1977. 
necesario señalar desde el inicio el límite particular al que se refiere el título de este trabajo. Mi propósito se ciñe específicamente al intento de delimitar el significado preciso que comporta la controvertida declaración platónica, consignada en República (R.) II 377a6, respecto a que la índole de los relatos literarios sería, por definición, la del carácter de pseûdos o de falsedad. El texto al que me refiero, y al que regresaré en el análisis, dice lo siguiente:

[Sócrates] Pero en las artes de las musas — dije- incluyes los discursos [lógous]... ¿̇o no?

[Adimanto] Al menos yo sí.

[S.] ¿Y no hay dos tipos de discursos, esto es, uno verdadero y otro, por el contrario, falso [pseûdos]?

[A.] Sí.

[S.] Aunque se ha de educar mediante ambos tipos. Al principio, sin embargo, educamos mediante los discursos falsos [pseudésin].

[A.] No entiendo a qué te refieres - respondió.

[S.] ¿No ves —dije yo- que primero contamos relatos [múthous] a los niños? Ahora bien, si no me equivoco este tipo de discurso constituye, por referirnos a él en conjunto, una falsedad [pseûdos]; aunque haya dentro de él también cosas verdaderas. ${ }^{2}$

\section{Presentación del problema}

Es bien sabido que en $R$. Platón critica el quehacer de los poetas alegando, entre otras razones, que sus obras constituirían algo "lejano a la verdad" (506c3; véase también 597e, 598b, 602c) e, incluso, algo que, sin más, no sería verdadero ( $378 \mathrm{c} 1)$. Declaraciones de este tipo, a las que es posible añadir otras de acento similar, ${ }^{3}$ parecerían delinear los rasgos de una tesis bastante provocativa por parte de Platón en la medida en que, según esas afirmaciones, la condición que correspondería a la literatura ${ }^{4}$ sería, básicamente, la de la falsedad. Una tesis de esta clase sólo puede representar, a ojos modernos, la expresión de una postura

${ }^{2}$ R. II 376e10-377a6. Excepto advertencia en contra, las traducciones son mías. He seguido el texto fijado por Burnet 1900-1907.

${ }^{3}$ Que no imita la verdad (598b); que es producida sin conocimiento de la verdad (599a); que no capta la verdad (600e).

${ }^{4}$ Sobre el uso del término "literatura" para referirse al tratamiento de la poesía en los escritos platónicos, véase Annas 1998 (1982), p. 273. También puede verse, en otra línea, la discusión de Notomi 2011, pp. 299-304 que considera anacrónico emplear el término "literatura" en el contexto platónico y griego en general, pues, por un lado, según la autora, éste incluye hoy géneros que no existían en el mundo antiguo (p.ej., la novela y el ensayo) y, por otro lado, porque la poesía significaba 
intolerante y excluyente. ${ }^{5}$ Sin embargo, si tal tesis resulta llamativa no lo es sólo por las connotaciones que pudiera traer consigo para nuestra sensibilidad estética actual, sino, antes, porque parece inconciliable también con otros elementos específicos de la propia postura platónica concerniente a la literatura. Dada esa disparidad, habría que sospechar, al menos, que el sentido de la calificación de pseûdos aplicado por Platón a la literatura ha de ser cuidadosamente especificado.

Concretamente sorprende -y es lo que me impulsa al análisis que emprendo a continuación- que Platón, en la sección 377a y ss., tras clasificar los relatos literarios entre los discursos falsos y censurar secciones enteras del corpus homérico-hesiódico porque narrarían falsedades, no rechaza de plano todo recurso a la literatura, sino que propone allí mismo emplear en la práctica educativa y política relatos semejantes a aquéllos: llama la atención, en otras palabras, que, al elevar su propia propuesta de material literario para reemplazar el pseûdos vigente, no haya exigido que el material nuevo fuese ahora alethés, sino que haya mantenido la propuesta de recurrir a relatos falsos. En este sentido, pseûdos constituiría, al parecer, una propiedad positiva de los discursos y éstos parecerían resultar, para ciertos efectos, adecuados $(378 \mathrm{e} 2-4)$. Naturalmente, podríamos preguntarnos en este punto en qué podría residir el aspecto positivo de la falsedad de los discursos literarios que Platón se propone utilizar y, antes aún, si la falsedad poseería entonces para Platón un valor al mismo tiempo positivo y negativo. En cuanto a esta última pregunta, se podría alegar que no sería ésta la primera vez que una misma noción adopta, en el corpus platónico, matices de signo contrario, pues Platón — se podría replicar — no es el tipo de autor que tienda a fosilizar los términos, acuñando categorías inalterables; nótese, en este sentido, que, en relación con los discursos, Platón menciona distintas variantes de lo falso, a saber, una falsedad que —como ya he indicado- contiene elementos verdaderos (377a5-6), una falsedad impura (382c1), una falsedad que intenta asemejarse a la verdad (382d3-4), una falsedad necesaria como una medicina (389b5) y una falsedad noble (414c1).

para los griegos mucho más de lo que el término "literatura" designa para nosotros, a saber, "enciclopedia, fuente de sabiduría de vida y de educación cívica". Especifico el sentido en que utilizo aquí el término en la nota 6.

${ }^{5}$ Como se sabe, Popper 1957, p. 59, ha hecho esta acusación. Para Popper, por ejemplo, el relato fenicio propuesto por Platón es una simple mentira propagandística para los intereses del Estado. En esta línea, entre otros, también Annas 1981, p. 167 y Crossman 1963. Una revisión de la postura de Popper puede verse en Schofield 2006, p. 298.

Diánoia, vol. LX, no. 74 (mayo de 2015). 
Pero hay aspectos problemáticos que no son meramente terminológicos y que, conectados a esta cuestión, requieren ser resueltos. Me refiero en concreto a que resulta desconcertante un escenario como el delineado líneas antes sobre el uso de discursos falsos cuando se lo confronta con aquellas otras afirmaciones platónicas concernientes a la prioridad absoluta de la verdad en el marco de la formación de los guardianes (485c4-d4) y a la necesidad de que la virtud de la veracidad impregne las relaciones entre gobernantes y gobernados en el Estado perfecto (389b-d). Bien podríamos preguntarnos en este contexto qué sentido tendría que un proyecto educativo, cuya meta reside en preparar a los individuos para una adecuada acogida de la verdad, se inicie precisamente con la narración de falsedades. Tal vez se podría apuntar que Platón sólo estaría pensando en usar esos relatos cuando se tratara de la formación del carácter de los niños y adolescentes, pues éstos no dispondrían todavía de la capacidad necesaria para recibir una formación dialéctica y serían por lo pronto sujetos de una formación exclusivamente ética; en tal medida, la literatura cumpliría un papel sólo provisorio en la educación y puramente subsidiario de la dialéctica, mientras que en la adultez el recurso a ella sería prescindible como una herramienta pedagógica ya innecesaria. No obstante, Platón sostiene lo contrario, esto es, afirma expresamente que también para los ciudadanos adultos será necesario componer relatos literarios (378d23) y, además de afirmarlo, señala un ejemplo de éstos que pertenecía ya al acervo cultural de su tiempo. Me refiero al relato fenicio, que explícitamente califica allí también de "falsedad" (414c1) y, pese a ello, parece proponerlo como relato literario que puede ser necesario con el fin de lograr el acuerdo de los ciudadanos adultos en la organización del Estado perfecto; ${ }^{6}$ más aún, no sólo parece proponerlo como instrumento adecuado para tratar a los ciudadanos en general, sino $-\mathrm{y}$ antes que a éstos- a los mismos futuros gobernantes. ¿Por qué censura Pla-

${ }^{6} \mathrm{La}$ adopción de la fórmula "relato literario" en mi texto se debe a que creo necesario dar cuenta del espectro semántico que el término "mito" —alternativa posible - tiene en castellano, pues con él designamos tanto el núcleo temático del relato perteneciente al bagaje común de la tradición y que, como tal, tiene una estructura semántica bastante estable, cuanto también la versión narrativa que cada poeta acuña con base en ese esquema temático y en la que introduce sus propias variaciones. La expresión "relato literario" no resulta una expresión anacrónica en los pasajes platónicos que examinaré en la medida en que el término mûthos, procedente de muthéomai - relatar, contar-, designa precisamente una leyenda o historia (Chantraîne 1968, pp. 318-319) y, en el corpus platónico, específicamente en pasajes claves para mi discusión es narratio ( $R$. II 377a) y, a su vez, muthologéo es narro en $R$. II 378c-e, 379a, 415a (Ast 1956, ad loc.). 
tón unos relatos literarios por ser falsos (pseûdeis) y, al mismo tiempo, propone el uso de otros que son de esa misma índole?

En síntesis, las respuestas a esto dirían que Platón, cuando afirma que la literatura es algo falso, se refiere fundamentalmente a (i) que ésta reporta ficciones en la medida en que narra acontecimientos y versa sobre personajes que no son reales, históricos, sino imaginarios (Ashbaugh 1991, p. 307; Cornford 1961, p. 66); o (ii) que incluye mentiras en la medida en que su autor incurre allí deliberadamente en la comunicación de falsedades (Ferrari 2008, p. 113; Schofield 2006, p. 283; Gill 1993, p. 40; Adam 1902(1969), ad 376e12-13); ${ }^{7}$ o (iii) que designa distintamente la índole fáctica del discurso o la índole normativa de los paradigmas propuestos en él, siendo la verdad o la falsedad normativas lo decisivo en la criba platónica de la literatura (Santa Cruz 2007, p. 276; Belfiore 1985, p. 49; Battin 1977, p. 165). En lo siguiente intentaré mostrar que, para una adecuada interpretación de la postura platónica relativa a la índole falsa de la literatura, es del todo relevante atender la sección 376d-379a. Esta sección, que la bibliografía especializada deja de lado con frecuencia demasiado rápidamente por centrarse en 382d, 389b y 414c, proporciona argumentos decisivos (i) para defender que Platón no califica de "falsa" la literatura meramente porque contenga ficciones y (ii) para apoyar que, si se quiere explicar la justificación platónica de recurrir a la falsedad en el caso de los relatos literarios, se hace necesario deslindar en la formulación platónica de 382d1-3 la referencia a dos niveles distintos de "verdad", el literal y el no literal. Si esto es correcto, entonces será también posible mostrar que (iii) Platón no trata la literatura como el medio propicio para divulgar ciertas falsedades que tenderían deliberadamente a la engañosa persuasión del público y que ni su crítica responde al hecho de que la literatura sea una serie de mentiras ni su propuesta poetológica contempla tam-

${ }^{7}$ Como se sabe, el término pseûdos admite tanto el significado de "falsedad" o "error" como el de "mentira" y también el de "ficción", lo cual hace que las dos lecturas mencionadas sean, desde este punto de vista, posibles. La ambivalencia del término griego pseûdos, que en general significa "falsedad", reside en que ésta se concibe en ocasiones como una falsedad no intencionalmente pronunciada y, en tal medida, el significado del término se acerca al de "error", mientras que, otras veces, se hace referencia con él a una falsedad pronunciada intencionalmente, esto es, a una "mentira" (Liddell, Scott y Jones 1996). Sobre la doble acepción de pseûdos en el contexto de la discusión de $R$. II, véase Gastaldi 1998, p. 346. Entre las traducciones al español, hace una interpretación afín a las mencionadas Eggers Lan, quien -si bien en 376e12-13 no traduce pseûdos como Adam por "mentira" - posteriormente emplea este término para las acepciones de $377 \mathrm{~d}-\mathrm{e}$, 382a-c, 389b, 414c1.

Diánoia, vol. LX, no. 74 (mayo de 2015). 
poco - contra lo que habitualmente se interpreta del gennaîon pseûdos, $414 \mathrm{c} 1$ - el recurso a lo que se designa como una "noble mentira".

\section{Pseûdos, eni de kai alethê: ¿significa pseûdos "ficción" en 376d-379a?}

La primera afirmación que recoge $R$. respecto al carácter falso de la literatura consta en la sección 376 d-379a del libro segundo. En ella se inicia el extenso análisis de la educación que, según Platón, el Estado debería proporcionar a sus futuros guardianes. La discusión sobre la literatura se introduce precisamente con motivo del examen de uno de los dos pilares de la educación griega: el que podría denominarse "cultural" y que, como se sabe, se basaba sobre todo en el contacto con las obras poéticas de la literatura vigente. Así, la conversación se detiene un buen momento en la cuestión del material literario que convendría emplear para la educación de los guardianes. El primer aspecto que se examinará en esta revisión es el de los relatos (múthoi) que tales obras comunican, y, puesto que esos relatos son un tipo de discurso (lógos), se procede al análisis mediante una distinción de las clases en que cabe diferenciar a los discursos en general y en la que se clasifican los relatos literarios (múthoi) en particular entre los discursos de tipo falso. El contexto general es el siguiente.

Los discursos — se dice- son de dos tipos, a saber, verdaderos o falsos; ahora bien, los relatos que se emplean en la primera crianza de los niños —advierte Sócrates- son del tipo falso aunque incluyan también ciertas verdades. Se trata, explica a Adimanto, de los mitos que madres y nodrizas cuentan a los pequeños. La narración de estos relatos tiene, aunque no siempre se reconozca así, una gran relevancia en la educación por dos motivos: porque con total espontaneidad contribuyen a la implantación de determinadas doctrinas (dóxas, 377b8) y porque lo hacen de manera sumamente eficaz, fijándose en la mente de los niños como una suerte de sello, o túpos. ${ }^{8}$ El peligro de que las dóxai comunicadas por esos relatos sean falsas es evidente: los futu-

${ }^{8}$ Como se sabe, el sentido original del término túpos designaba el molde que se empleaba en la producción plástica en general, y en la escultura en particular, concretamente para fabricar a partir de él una serie de representaciones con el mismo diseño. En esta sección, Platón se vale del trasfondo plástico del término túpos para aludir a la incidencia de los relatos mitológicos en el alma de sus destinatarios, ya que - según Platón- estos discursos efectuarían también una auténtica plasmación o formación de los receptores, esculpiendo sus almas como si éstas fueran un material moldeable o, en otras palabras, como sujetos a los que se puede inculcar creencias, deseos y aspiraciones a través de la impresión de ciertos patrones. Para

Diánoia, vol. LX, no. 74 (mayo de 2015). 
ros guardianes crecerán firmemente convencidos de ideas erróneas que sólo con dificultad podrán luego revisar y rectificar. Por eso es clave, según Platón, cribar el material literario vigente con el fin de examinar el contenido que comunican y eliminar todo lo que sea inconveniente (dóxas enantías, véase 377b5-9). Naturalmente, las obras de Homero y Hesíodo son principales en este sentido, pues ellos han compuesto los múthous pseudeîs (377d6-7) más importantes (mégiston, 377e7). De ese corpus literario Sócrates selecciona algunos pasajes con los que ilustra qué hay que censurar en las narraciones poéticas: las escenas en que los dioses aparecen realizando acciones inmorales deben eliminarse del material pedagógico y hay que prohibir su empleo en la educación del Estado. ${ }^{9}$ Por el contrario, y ésta es la propuesta platónica, “debe ponerse el máximo cuidado en los primeros relatos que los niños oyen, de modo que escuchen los mitos más bellos que se hayan compuesto en vista a la excelencia" (378e). ${ }^{10}$ Para la criba del material literario existente y para la elaboración de nuevos materiales adecuados se procede por el momento a indicar sólo las pautas básicas que habrán de orientar esas tareas, esto es, se señalan los túpoi que los relatos realmente educativos deben incorporar y comunicar. En cambio, la labor poética de crear los relatos mismos es algo que no compete ni a Sócrates ni a Adimanto pues, en este momento, asumen exclusivamente la función de diseñadores de un Estado y no la de poetas compositores de mitos o relatos literarios (379a).

Las indicaciones que Platón consigna al inicio de esta sección, es decir, las afirmaciones ya citadas en torno a los discursos, a su clasificación binaria y a la clase peculiar en que se encuentran los relatos literarios, son de gran relevancia para nuestro tema. En esos pasajes Platón indica con toda claridad que los relatos literarios se clasifican entre los discursos falsos. Hasta aquí la afirmación platónica suena extraña, e incluso injusta, pero eso no es todo: el escenario se complica porque inmediatamente Platón añade que, además de ser falsos, los relatos literarios encierran ciertas verdades. Esta advertencia de que los relatos literarios no son del tipo de discurso puramente falso, sino que tienen elementos verdaderos, ha llevado a suponer a algunos estudiosos que en este pasaje el predicado "falso" no debería entenderse como "no verdadero" o erróneo, sino que más bien en el sentido de "ficción”. Así, por ejemplo,

un tratamiento de las tipologías en sede platónica, véase Bordt 2006, pp. 50-51, y Ferrari 1998, pp. 402-425.

${ }^{9}$ Se alude, por ejemplo, a las terribles acciones que Hesíodo atribuye a los dioses al narrar sus orígenes. Véase, por ejemplo, Hesíodo, Theog. 154-182 y 459 y ss.

${ }^{10}$ Esta traducción es de Eggers Lan. 
Cornford 1961 (ad 376e12-13) sostiene que este término designa las obras que son producto de la imaginación y de la fantasía del poeta, y que pueden haber sido compuestas en forma de mitos, alegorías, fábulas, parábolas, etc. ${ }^{11}$ Los relatos literarios serían así pseûdoi porque serían narraciones imaginarias cuyos argumentos no corresponderían a hechos efectivos, sino que procederían de un ejercicio de la fantasía del poeta. Según una lectura de este tipo, la advertencia de Sócrates de que "este tipo de discurso [los mitos] constituye, por referirnos a él en conjunto, una falsedad; aunque haya dentro de él también cosas verdaderas" habría de entenderse en el sentido de que los relatos literarios, a diferencia de los otros discursos, no deberían catalogarse según el criterio de verdad o falsedad, sino mantenerse, como producto estético, al margen de esa catalogación; la noción de "ficción" daría cuenta adecuadamente, desde este punto de vista, de la independencia que tendría el relato literario respecto de cualquier valoración epistemológica, la cual sería, además, una valoración reductiva e improcedente en el ámbito poetológico. En este sentido entiende Ashbaugh la "verdad" de las ficciones: "es la verdad de las imágenes mismas; es su capacidad de parecer como bellos fenómenos coherentes, ricos en detalles y temporalmente completos" (Ashbaugh 1991, p. 309).

Con respecto a la supuesta autonomía estética de los relatos literarios que se seguiría de su índole ficticia, Ferrari 2008 ha advertido ya - a mi modo de ver, correctamente- el prejuicio moderno que implica emplear el término "ficción" para traducir el pseûdos platónico. Con el concepto de "ficción" designamos un producto artístico que dispone de "una vida en cierto sentido propia" (p. 98), esto es, cuya verdad o falsedad y cuyo valor moral no es aquí una cuestión relevante, sino que esa autonomía, en cambio, es un valor positivo; pero, en el horizonte cultural de Platón, en su lengua y en su propia concepción de la poesía, no hay equivalente alguno para este concepto (p. 108). Gill 1993, en esta misma línea, ha demostrado que la distinción verdadero/falso de Platón no es correlativa en este contexto a nuestra noción de discurso ficticio. Gill afirma que nuestra idea de "ficción" tendría por base la valoración positiva de la capacidad que tenemos los receptores de una obra para identificarnos imaginariamente y de modo no evaluativo con personajes irreales; modo de acceso que, en nuestro paradigma cultural, sería válido para procurar una expansión interesante de la propia cosmovisión. En esa medida, la obra literaria parecería no tener, a ojos

${ }^{11}$ Ashbaugh 1991 (p. 307, n. 1) apoya esta interpretación al invocar la aparición de pláttein y plásma en 377 a y $377 b$.

Diánoia, vol. LX, no. 74 (mayo de 2015). 
modernos, ninguna pretensión de verdad en sentido objetivo (p. 84). En cambio, el carácter performativo de que dispone la literatura en el mundo antiguo, y también en Platón, contradice, según Gill, ese carácter no evaluativo con que el receptor accede a la cosmovisión propuesta en una obra literaria y, por lo tanto, se diferencia fuertemente también de nuestra idea de "ficción".

Sin necesidad de ir lejos, la misma sección 376e10-377a6 proporciona la posibilidad de argumentar decididamente contra la interpretación de pseûdos como "ficción". Me refiero a que no es posible atribuir a Platón la idea de que los relatos literarios son un tipo de discurso ficticio al margen de cualquier clasificación epistemológica pues, como se comprueba en ese texto, la única clasificación posible de los discursos para Platón es aquí (a) binaria (dittón, 376e12) y lo es (b) según los criterios de verdad o falsedad. Si los relatos literarios fueran, según Platón, una ficción que, como tal, escapara a la distinción epistemológica verdadero/falso, habría indicado expresamente una tercera especie (eîdos, 376e12) de discurso que, a diferencia de la especie verdadera y de la falsa, no sería, esta vez, ni verdadera ni falsa, sino que permanecería al margen de esta valoración. Pero no es esto lo que consta en el texto. En realidad, lo que hace Platón, lejos de señalar una nueva y tercera especie de discursos, es identificar, en la especie pseûdos, un subgénero mixto que incorpora en lo falso algunos ingredientes verdaderos. Este subgénero de la especie falsa no cancela, sino que mantiene la distinción inicial. Por lo tanto, tampoco puedo aceptar la lectura de Ashbaugh 1991 (p. 312), quien defiende que los relatos literarios guardan para Platón una posición intermedia entre las narraciones verdaderas (las históricas) y las puras mentiras.

Naturalmente, si esto es correcto, lo que queda por explicar es cómo entender y dar una explicación adecuada que haga justicia a la descripción platónica del relato literario como algo falso que simultáneamente encierra verdad. Analizo esta cuestión en la sección 4. Antes quiero consignar y discutir los argumentos principales de una segunda postura que defiende en sus versiones más duras que Platón tomaría la literatura por pseûdos en el sentido de "mentira".

3. Pseûdos en tê psuchê y en toîs lógois: ¿puede pseûdos significar "mentira" en 381e-382e?

Pocas páginas más adelante aparece en el texto una nueva especificación sobre un tipo de pseúdos que se relaciona con los relatos literarios. Veamos cómo transcurre el argumento. 
En la sección previa a 381e-382e se sostuvo expresamente que la tarea de Sócrates y Adimanto, ahora fundadores de un Estado y no poetas ni compositores, radicaba de modo específico en la tarea de identificar las pautas esenciales (túpoi) que deberían servir para orientar la composición de relatos literarios en vistas a que sean adecuados como material educativo. Las pautas que se identifican son dos, y ambas conciernen a la naturaleza de la divinidad. Tras acordar la segunda directriz relativa a la representación de la divinidad en las artes, es decir, que el dios no es un hechicero (380d1) que nos engañe alterando su aspecto y presentándose bajo diversas figuras sino que es simple y veraz (383e10), se plantea la cuestión de si, a pesar de ello, sería posible suponer el siguiente escenario: que, aun cuando alterarse no fuera propio de la naturaleza divina, en sí misma ya plenamente perfecta, cabría pensar que los dioses mediante embrujos nos hicieran creer (381e8) que cambian de aspecto. A esto Sócrates responde -y eso es lo que interesa para nuestra discusión- que los dioses aborrecen pseúdesthai, esto es, que detestan engañar (382a1). ${ }^{12}$ Como para explicar mejor en qué está pensando y qué es lo que los dioses odian exactamente, Sócrates introduce una cláusula en la que deslinda dos tipos de pseûdos: el primero, según dice el texto, consiste en un estado mental específico o afección del alma, la ignorancia (amathê eînai; he en têi psuchêi ágnoia he tô̂ epseusménou, 382b), odiada tanto por los dioses como por los hombres y que es el pseûdos al que denomina toûto hos alethôs pseûdos, esto es, el genuino pseûdos o, líneas más abajo (382c), tôi ónti pseûdos, el pseûdos real. ${ }^{13}$ En cambio, el segundo tipo sólo reside en las palabras (tò en toîs lógois, 382c) y no afecta al alma, por lo que no consiste en una forma de ignorancia, sino sólo en una imitación (mímema, 382b) o imagen (eídolon, 382b) de ella. A diferencia del anterior, este tipo de pseûdos no es odiado por los dioses e incluso puede resultarles a los hombres en ocasiones un recurso necesario (chrêsimon, 382c): (i) cuando se trata con enemigos, (ii) cuando se trata con amigos que, en estado de locura $\mathrm{u}$ otro tipo de insania, pretenden hacer a otros o hacerse a sí mismos al-

12 Entiendo aquí pseúdesthai como "engañar” porque se encuentra conectado con el participio exapatôntes inmediatamente anterior.

${ }^{13}$ La frase tò hôs alethôs pseûdos habitualmente se traduce como "la verdadera mentira". Si bien es evidente que con esta expresión, que reúne a un tiempo los opuestos "falso" y "verdadero", Platón tiene la intención provocadora de subrayar la paradoja de un fenómeno, lo que pretende también es señalar con hôs alethôs un fenómeno que sería auténticamente pseûdos y distinguirlo, a su vez, de otro que no sería realmente tal. A este último lo denomina ou pánu ákraton pseûdos, es decir, la falsedad que no es completamente pura (382c1). 
gún mal, y (iii) cuando, por desconocer la verdad acerca de los hechos del pasado, componen al respecto relatos literarios (en taîs muthologíais, 382d1) en los que buscan asemejar lo más posible pseûdos a la verdad. Evidentemente — se concluye- los dioses no necesitan ningún tipo de pseûdos en ninguno de estos casos y, por consiguiente, cuando se declara que los dioses detestan engañar, ello significa que aborrecen tanto la falsedad procedente de la ignorancia como la que procede de una decisión deliberada, aunque a esta última la toleran en ciertas circunstancias humanas (382e).

Es precisamente en este marco de la identificación de una falsedad deliberada donde, como he dicho, se ha querido ver una equivalencia de pseûdos con "mentira" y, en la medida en que la composición de relatos literarios sería un caso de ese pseûdos deliberado, se ha interpretado que también los relatos literarios serían para Platón uno de los casos de "mentira" legítima.

Ahora bien, el hecho de que Platón haya incluido la composición de relatos literarios entre ciertos casos de falsedad verbal deliberada no es suficiente para sostener que entonces esos discursos son, sin más, una "mentira", pues ésta requiere no sólo el ingrediente de la deliberación, sino también, como indicó Platón ya en Hipias Menor (Hp. Mi.), el conocimiento de la verdad correlativa que se desea distorsionar. Esta segunda condición no se cumple en el caso de los relatos literarios. El argumento socrático presentado en $H p$. Mi. defiende, se recordará, que el veraz no sería mejor ni distinto del mentiroso en la medida en que sólo una misma e idéntica persona, el que sabe, es capaz tanto de mentir, es decir, falsificar algo no por mero error, como también de decir la verdad (Hp. Mi. 367d). Mediante el ejemplo del cálculo aritmético, Sócrates ilustra la idea de que, para poder mentir con éxito y ser capaz de hacerlo en todas las ocasiones requeridas y no decir, en cambio, por casualidad y sin querer la verdad, se vuelve estrictamente necesario tener conocimiento de esa verdad que se pretende falsear, de manera que sólo estará en condiciones de mentir quien sepa efectivamente sobre el asunto que se trata en cada caso. A diferencia de la ignorancia, la mentira supone así incurrir deliberadamente en la falsedad, como se observa en $R$. II, y esto a su vez sólo es posible, como insiste Hp. Mi., si se dispone del conocimiento pertinente del tema sobre el que se profiere esa falsedad. ${ }^{14}$ Ahora bien, hay que advertir que, desde esta tipificación de la "mentira" que incluye la deliberación y el conocimiento del asunto, el caso de la composición de los relatos literarios como tò en toîs lógois

${ }^{14}$ Así lo señaló ya Santa Cruz 2007, p. 284.

Diánoia, vol. LX, no. 74 (mayo de 2015). 
pseûdos no puede leerse en el sentido de una "mentira" verbal. Platón mismo nos indica eso en la descripción de esa tercera circunstancia, pues allí anota de manera explícita que, al componer relatos literarios, se procura asimilar la falsedad a la verdad porque no se sabe (dià tò mè eidénai, 382d1-4) cómo han ocurrido los hechos antiguos. ${ }^{15}$ Aquí hay dos aspectos contrarios a la equiparación de este tercer caso de tò en toîs lógois pseûdos con la mentira, a saber, (i) el hecho de que se habla sobre algo que no se sabe, esto es, se desconoce la verdad del asunto en cuestión o, en otras palabras, la verdad correlativa al tema del que no se sabe y (ii) el hecho de que, a diferencia de la mentira que parte de lo verdadero y sólo desde allí pasa a distorsionarse, aquí el movimiento de asimilación es inverso, ya que su punto de partida es lo que se supone que ha de resultar falso por versar sobre algo desconocido procurando llegar, a su vez, a algo que se asemeje a otra cosa que sea verdadera. En lo que concierne a la composición de relatos no se dice que el escritor sepa la verdad de cómo han sido las cosas en la antigüedad y que, a pesar de ello, ofrezca una versión diversa, distorsionada de esos acontecimientos; lo que se dice es, por el contrario, que el poeta, precisamente por ignorar este asunto, confecciona un relato que no podrá ser verdadero, pero que, con todo, intenta brindar una falsedad lo más semejante posible a la verdad.

El objeto de esa ignorancia, lo que se desconoce, son los hechos antiguos (tà palaiá): el poeta no dispone de lo que cabría denominar la verdad histórica del asunto, lo relativo a los hechos y al modo como han sucedido (hópei [...] tôn palaiôn); y, en tal medida, hay que concluir que respecto de esa instancia el poeta no miente, sino que lo que el poeta hace, según Platón, es inventar una versión de esos acontecimientos; y, como es lógico, entre inventar una narración y mentir sobre un asunto hay una distancia notable, lo cual impide calificar el tercer caso de tò en toîs lógois pseûdos como "mentira". ${ }^{16}$

\section{Deslindamiento de niveles en los relatos literarios: R. II 376d-379a}

Por los motivos aducidos, parece claro hasta aquí que el caso de la falsedad de los relatos literarios no puede tratarse, sin más, como un tipo de "mentira". Ahora bien, la fórmula de 382d1-3 respecto a los relatos no deja de ser un tanto paradójica. Allí se nos dice que su falsedad sería útil cuando: (1) por desconocer la verdad sobre el modo como sucedieron

${ }^{15}$ En términos casi idénticos Hp. Mi. 367a3: dià tò mè eidénai. Véase, en este sentido, Belfiore 1985, pp. 49-50.

${ }^{16}$ Esto ha sido leído así ya por Santa Cruz 2007, p. 282. 
los hechos en la antigüedad (2) asimilamos esa falsedad lo más posible a la verdad. Resulta extraño que Platón afirme que en la composición de estas narraciones se asimile la falsedad a la verdad, cuando inmediatamente antes ha anotado que desconocemos esa verdad. Pero ise refiere efectivamente en los dos casos a la misma verdad? Ésta no parece ser una lectura muy viable, pues por lógica sería paradójico intentar asimilar una cosa a otra que se ignora. Más bien hay que suponer que la verdad a la que Platón se refiere en el caso de (2) es distinta de la verdad a la que se ha referido antes en (1), de manera que, cuando dice que en las narraciones de los acontecimientos antiguos asimilamos la falsedad a la verdad, no incurre en contradicción, sino que quiere decir que el desconocimiento de cómo han sucedido esos hechos antiguos nos lleva a intentar ofrecer una versión de ellos compuesta en conformidad con una verdad que, sin embargo, no es relativa a los hechos. ${ }^{17}$ Además, la verdad de (2), a diferencia de lo que se consigna en (1), sí se conoce y, si es a ella a quien se intenta hacer semejante la falsedad del relato, parece ser algo que ha de desempeñar la función de patrón para confeccionar la narración relativa a los hechos. Creo, por esto, que hemos de leer la referencia consignada en 382d1-3 como una formulación bajo el supuesto, no explícito, de que en los relatos literarios se combinarían dos niveles de "verdad" y "falsedad": uno, relativo a los hechos, histórico, y otro que no lo es. En otras palabras, habría una instancia que concierne a la narración de sucesos de un pasado lejano cuya verdad necesariamente se ignora y otra instancia que no consta de hechos históricos y de acuerdo con la cual, según Platón, hay que inventar una versión narrativa de aquéllos.

Ya Battin (1977), y otros después de ella, ${ }^{18}$ proponía diferenciar niveles para interpretar correctamente lo que en cada caso Platón califica de falsedad en la literatura. Según Battin, si se advierte que el uso de los predicados "verdadero" y "falso" puede aplicarse para (1) denotar que una proposición describe de forma adecuada o no un estado de cosas, o (2) para señalar que algo es o no un ejemplar paradigmático entre los de su clase, hay que concluir que estos usos originan un sentido fáctico y otro normativo de ambos predicados. Battin muestra que Platón usa

${ }^{17}$ En efecto, puesto que en (1) se ha declarado expresamente cuál es la verdad que se dice desconocer, es decir, que se trata de la relativa a los hechos que se narran y que, por eso, cabría denominar como verdad "histórica", y puesto que la verdad de (2) no es la misma que la de (1), hay que suponer, creo yo, que la verdad a la que se refiere en (2) no concierne a hechos históricos.

${ }^{18}$ Entre quienes cabe mencionar, por ejemplo, a Halliwell 2000, p. 103; Santa Cruz 2007, p. 276, y Casnati 2011, p. 60.

Diánoia, vol. LX, no. 74 (mayo de 2015). 
esos dos sentidos y remite para ello a la ontología de las formas de $R$. X. A partir de esta distinción, la autora advierte que, puesto que hay dos sentidos diferentes de los predicados "verdadero" y "falso" y que ambos se usan en Platón, para poder interpretar adecuadamente las referencias platónicas a la poesía es estrictamente necesario desambiguar el sentido en que se los emplea en cada caso. Battin defiende que, cuando Platón critica la falsedad de la literatura, podría estar haciendo referencia no sólo, ni principalmente, al hecho de que ella no describe adecuadamente los estados de cosas del mundo, sino, más bien, y esto sería lo más preocupante para Platón, al hecho de que la poesía no logra representar paradigmas en la medida en que, por no tener trato directo con las Formas, sus representaciones fallan siempre en algún aspecto al intentar ofrecer modelos genuinos.

Ahora bien, sin necesidad de recurrir al libro final de $R$. y a su ontología de las Formas, sino manteniéndonos en el contexto de este mismo libro segundo, ya la sección $376 \mathrm{e}-379 \mathrm{a}$, si se lee con atención, ofrece indicios claros de que Platón discurre con un deslindamiento de niveles, y esos indicios concuerdan perfectamente con la anotación de 382d1-3.

En efecto, esa distinción binaria de los discursos en verdadero y falso que vimos en $R$. II y la especificación para el caso de los relatos literarios - "este tipo de discurso constituye, por referirnos a él en conjunto, una falsedad; aunque haya también dentro de él cosas verdaderas"- vuelven a ser aquí clave. También en este pasaje, como en $382 \mathrm{~d} 1-3$, sucede que, si no es meramente contradictorio, hay que suponer que en un mismo relato podemos tener dos niveles distintos a la vez, y entonces un nivel puede ser verdadero $\mathrm{y}$, al mismo tiempo, otro nivel puede ser falso, de manera que un relato, aunque falso, puede también encerrar verdades. Cuáles son estos niveles y en qué consisten exactamente es una cuestión que puede responderse si observamos un segundo aspecto que aparece en la misma sección 376e-379a, a saber, la distinción entre los contenidos "doctrinarios" (dóxas) de un relato y las diferentes versiones narrativas que pueden ofrecerse de él. La frecuencia con que aparece la idea de túpos en esta sección evidencia que Platón centra su criba de la literatura en las creencias transmitidas por los relatos y que son inculcadas en sus jóvenes destinatarios como una impronta, mientras que las narraciones particulares que dan curso a esas creencias no son, de manera aislada, lo realmente decisivo en su crítica. De hecho, lo que Sócrates cita como problemático en toda esta sección no es el hecho de que los elementos narrativos no sean ciertos en el sentido de que sean ficticios o de que no sean históricos, sino que transmiten una creencia o núcleo tipológico (por ejemplo, la relación entre Cronos y 
Urano) que no se corresponde con la realidad que pretenden representar (por ejemplo, con la naturaleza divina).

Desde esta perspectiva, es posible conectar esta distinción "núcleo tipológico-narración" con el deslindamiento de niveles que habría en el relato literario y advertir que, mientras que la versión narrativa puede no ser cierta en el nivel literal debido a la ignorancia que tenemos de cómo sucedieron los hechos antiguos, el nivel no literal que, en cuanto contenido doctrinal, es diferente de ella, puede ser, al mismo tiempo, verdadero. En la medida en que la narración, aun cuando sea falsa, puede componer y transmitir un contenido verdadero, el empleo de esa falsedad —aunque sólo de esa específica "falsedad"— es legítimo para Platón.

Hay que notar que, si bien el deslindamiento de niveles se hace especialmente claro en los momentos en que Sócrates examina de manera crítica los pasajes literarios de distintos autores, se constata que también cuando hace referencia a la necesidad de crear una nueva literatura emplea esa misma distinción. Por ejemplo, cuando su interlocutor le pide que indique de manera concreta cuáles son los relatos que habrán de aceptarse en el Estado perfecto y lo apremia para que no se contente con señalar sólo las pautas generales, Platón lo hace puntualizar:

Ahora no somos poetas tú y yo, Adimanto, sino fundadores de un Estado: y a los fundadores de un Estado sólo les compete conocer las pautas (túpous) con base en las cuales conviene que los poetas compongan sus mitos y en contra de las cuales no podrán volverse a la hora de [realizar] creaciones; mas a [los fundadores] mismos no les compete componer relatos. (379a1-4)

Diseñar las pautas para una literatura adecuada, lo cual implica saber (eidénai) sobre las tipologías, es distinto a componer los relatos mismos (muthologeîn); y es distinto también el nivel tipológico en un relato del nivel mitológico o, como lo he denominado antes, literal.

En este sentido, hay que señalar también que antes, cuando Adimanto pregunta sobre los mitos que Sócrates acaba de calificar de $p s e \hat{u}$ dos (377c), éste introduce una anotación que muestra a las claras que, si bien puede haber versiones diferentes de los relatos, lo central en ellos es, sin embargo, el núcleo tipológico en que se inspiran: "En los mitos mayores — respondí- podremos observar también los menores, pues el túpon ha de ser el mismo e idéntica la influencia tanto de los mayores como de los menores" (377c8-d1). Lo que estas palabras de 
Sócrates suponen es que los relatos pueden adoptar versiones diferentes y basarse al mismo tiempo en un patrón idéntico y que, en esa medida, es perfectamente posible deslindar, al menos de forma analítica, ambos elementos. Esto supone también que es precisamente a través de esas versiones como tiene lugar la comunicación de creencias que transmite la literatura y que tanto preocupan a Platón.

A estas referencias al deslindamiento de niveles se le suma una última que claramente se relaciona con el sentido de un relato y que obliga a pensar que en toda esta sección efectivamente Platón considera los relatos literarios desde el prisma de sus eventuales niveles de sentido. En 378d6-8 declara de manera expresa que los relatos inadecuados no deben emplearse en la educación "ni siquiera aunque hayan sido compuestos con o sin sentido alegórico (en huponoíais, áneu huponoiôn). El niño, efectivamente, no es capaz de discernir el sentido que está encubierto (hupónoia) del que no" (378d6-8). ${ }^{19}$ Esta referencia al sentido encubierto o profundo (hupónoia) de un relato muestra definitivamente que, en estos pasajes, el tratamiento platónico de la literatura considera diversos niveles de sentido como instancias que constituyen una obra literaria - aquí, específicamente, se contempla la posibilidad, ya reconocida en su tiempo, de que uno de esos niveles sea de tipo alegóricoy que la acusación de falsedad se ubica en el marco de esa distinción. Por consiguiente, para leer adecuadamente esa acusación es imprescindible identificar a cuál de los niveles, si al literal o al no literal, se refiere Platón en cada caso.

Algo similar encontramos ya en Ion 530c1-5, donde se menciona un nivel literal (tà épe) correlativo a lo que los rapsodas aprendían perfectamente de memoria y otro nivel correspondiente a lo que el poeta con sus palabras quiere dar a entender, es decir, al sentido (diánoian) de sus versos o nivel no literal del discurso literario. Flashar 1958 (pp. 24-25) sostiene que la referencia a diánoian en estos pasajes del Ion es paralela al Simposio 3, 5-6 de Jenofonte, donde Sócrates señala que los rapsodas no entendían la alegoría (hupónoia) en las obras literarias. Con este

${ }^{19}$ En este pasaje tenemos las tres únicas veces en que aparece el término hupónoia en todo el corpus platónico. Para la equivalencia de hupónoia y "alegoría", véase Plutarco, De aud. poet., 19e: el vocablo hupónoia se consideró ya en la Antigüedad sinónimo de alegoría, término que Platón no emplea nunca. A pesar de ello, se sabe que la práctica de la interpretación alegórica en tiempos del filósofo era muy común, por ejemplo, en la lectura de las obras de Homero. Para un estudio de referencia en relación con la cuestión de si hay o no en la obra platónica la identificación de un sentido alegórico de los textos, puede consultarse Tate 1929, pp. 161-169. 
empleo sinonímico de ambos términos, se tendría aquí un claro antecedente de las distinciones de $R$. II, es decir, de los niveles "literal y no literal", por un lado, y la identificación de un sentido alegórico dentro del nivel no literal, por otro.

En síntesis, para aclarar la polémica postura de Platón en relación con la índole de la literatura que se resume en una afirmación como la de 377a ("este tipo de discurso [los mitos] constituye, por referirnos a él en conjunto, una falsedad [pseûdos]; aunque haya dentro de él también cosas verdaderas"), hay que leer las valoraciones "verdadero" y "falso" como adjetivos que pueden referirse a dos niveles distintos de la obra literaria. Calificar la literatura como algo pseûdos no significa entonces que Platón la considere un cúmulo de mentiras ni que los relatos literarios, por ser meramente ficticios, eludan, para él cualquier valoración epistemológica. La calificación de pseûdos en este contexto poetológico parece aplicarse más bien a dos niveles diferentes que constituirían una obra literaria, a saber, o al sentido literal de lo dicho en el relato o a su contenido mismo, que rebasaría esa expresión literal. Desde esta perspectiva puede resolverse la paradoja aparente en que incurriría Platón cuando al mismo tiempo censura el uso de ciertos relatos literarios porque son falsos y propone también, a pesar de ello, el uso de otros relatos literarios igualmente falsos; la primera actitud tendría que ver con la falsedad del contenido de esos relatos — falsedad que para Platón debe rechazarse-, mientras que la segunda estaría conectada con la falsedad de los elementos narrativos involucrados en el relato literario y que, a diferencia de la anterior, no sólo no es rechazable, según Platón, sino que puede ser, a su modo de entender, una vía adecuada para transmitir contenidos verdaderos. Es en este escenario como creo que se ha de entender también el gennaîon pseûdos que se menciona páginas más adelante.

\section{El gennaîon pseûdos}

La cuestión de los relatos literarios y su falsedad reaparece cuando Sócrates menciona uno de ellos, de procedencia fenicia, que al parecer podría resultar útil, según él, como relato para los futuros gobernantes y que, en clara referencia a las secciones previas sobre la falsedad, denomina gennaîon pseûdos (414c1). Platón conecta este gennaîon pseûdos con la falsedad que puede ser útil (en déonti, 414b9, remite a chrêsimon, 389b5) y lo hace de manera explícita (hôn dè nûn elégomen, 414b9); a través de esta referencia (una falsedad que sería útil como medicina 
preventiva: phármakon, 389b5), ${ }^{20}$ Platón reenvía expresamente (ei gàr orthôs elégomen árti, 389b5), a su vez, a la falsedad verbal de los relatos sobre un pasado muy remoto (382d1-3) que también incorpora una cláusula de reenvío, a saber, hais nûn dê elégomen taîs muthologíais. Ésta es la última referencia que remite, finalmente, a 377a5-6, b5-12, c4, d6, 379a3, es decir, a la sección en que se discute la aceptabilidad de los relatos literarios vigentes.

Es corriente ya en las versiones en distintos idiomas traducir la expresión gennaîon pseûdos por "noble mentira" y habitualmente se da por hecho, sin más, que con ella Platón propone utilizar para persuadir a ciudadanos adultos — y ya no sólo a niños en la primera educación— ${ }^{21}$ una mentira que sería legítima por el noble fin político que apoyaría. Pero ¿realmente se trata aquí de una "mentira"? ${ }^{22}$ Antes he defendido que la tipificación de los relatos literarios en 382d1-3 no sirve, en realidad, para interpretar que Platón se refiere allí a una "mentira", ni siquiera a la que no es una mentira genuina, sino sólo verbal. Ahora bien, si el caso del relato fenicio, tal como aparece en 414c-415d, corresponde a una suerte de mentira noble, entonces mi argumentación anterior queda automáticamente invalidada por este ejemplo de relato que el mismo Platón incorpora. Examino esta cuestión en esta última sección.

Sócrates invoca el relato fenicio para reforzar la convicción de que en Kallípolis todos los ciudadanos detentarán, por un lado, una igualdad radical y que, por otro, serán llamados a desempeñar en ese Estado una diversidad de funciones, las cuales guardan entre sí una relación de solidaridad y complementariedad. En efecto, el argumento inmediatamente anterior había mostrado la importancia de que el gobierno del Estado se encargara a aquellos individuos que ofrecieran pruebas firmes de que habían internalizado la convicción verdadera de que su propio bien está estrechamente ligado a la buena fortuna del Estado (412d10-e2); en otras palabras, sólo habrán de gobernar quienes con-

${ }^{20}$ Schofield 2006 (p. 285), compara esta idea de que pseûdos funcione como phármakon con el famoso dictum de Marx que identifica la religión con el opio del pueblo.

${ }^{21}$ Este aspecto compromete la tesis de Casnati 2011 (pp. 58 y 67), según la cual la aceptabilidad de los discursos falsos tendría que ver con el uso propedéutico que se haría de ellos.

${ }^{22}$ Schofield 2006 (p. 283), defiende, por ejemplo, que este relato -la noble mentira - es el texto clave para apoyar su tesis de que, en la utopía platónica, la religión prescribe una ideología que articula el sistema de creencias común para asegurar la cohesión social. 
sideren como bien propio el logro efectivo de una adecuada organización y funcionamiento social. Esta disposición como tal es, insisto, considerada verdadera, y no se acepta solamente en virtud de su conveniencia desde un punto de vista pragmático. ${ }^{23}$ Hay que consignar, en este sentido, que el problema que plantea el relato fenicio no reside en el núcleo tipológico que comunica, pues éste se considera verdadero, sino en el nivel narrativo o literal que debería darle cauce. Como se afirma en Leyes ( $L g$.) 663e al mencionar también el relato fenicio: "bella es la verdad, y firme; pero al parecer no persuade fácilmente", motivo por el cual se considera oportuno contar con algún relato que refuerce la creencia anterior, es decir, la creencia de que, si bien todos los ciudadanos son iguales, sólo algunos de ellos presentan las cualidades imprescindibles para hacerse cargo de la función de gobierno. En este marco se introduce una narración compuesta, en realidad, por dos mitos, cuya difusión sería corriente ya en otras ciudades, a diferencia de lo que se registra en Atenas, donde no tiene aceptación por ser demasiado fantástico. Tras un forcejeo tendiente a poner de manifiesto la escasa apreciación que Sócrates le concede a tan fantástica narración (414c8), acaba por exponerlo esquemáticamente.

La primera parte ofrece una versión de cómo habría tenido lugar la fundación de Tebas. ${ }^{24}$ Ese hecho, según el relato, no habría sucedido como se había creído ilusoriamente hasta ese momento; en realidad, todo lo aprendido sería algo así como un sueño. Ellos, los ciudadanos de Tebas habrían sido, en verdad, concebidos, moldeados y dados a luz ya adultos con todas sus armas y demás enseres por la tierra, madre por igual de todos. Por eso, serían todos hermanos entre sí y tendrían en común el deber de cuidar y defender el territorio de su ciudad. Esta parte del relato apuntaría a refrendar la idea de que originariamente, esto es, desde su fundación, el Estado es algo, a la vez, propio y común a todos, cuyo bien, por lo tanto, ha de ser del interés común e individual. Esto que podríamos denominar la igualdad radical de los ciudadanos encuentra su contrapunto en lo que se podría llamar la diversidad y

${ }^{23}$ Esa opinión se considera verdadera en 412e7, 413a2, y es con esta intención que se plantea la posibilidad de inventar (pseudoménous tiene valor condicional, 414c1) un relato que los vincule desde su origen con un deber específico ante el Estado.

${ }^{24}$ Tema que aparece, por ejemplo, en Eurípides, Phoenissae 931 y 935. El relato fenicio es un mito de autoctonía sobre la fundación de Tebas por parte de Cadmo, según el cual los tebanos habrían nacido de Gea. Este mito "genético" es invocado no sólo por Platón, sino ya antes — como muestra Vernant 1973, p. 36- por Hesíodo con el objetivo de explicar la división estructural y la complementariedad de los estatutos políticos con que se organiza una sociedad.

Diánoia, vol. LX, no. 74 (mayo de 2015). 
complementariedad funcional. La segunda parte del relato se dirige a apoyar esto segundo, y adopta la forma de una exhortación y de una adaptación del mito de los metales. ${ }^{25}$ Los ciudadanos son todos, según se dijo, hermanos entre sí; el dios, sin embargo, habría introducido en la creación de los individuos mezclas de distintos metales. En quienes debían ocuparse de gobernar introdujo oro; en sus auxiliares, plata; en los que habían de ser los distintos tipos de artesanos puso hierro y bronce. Habitualmente cada uno de estos tipos de hombre engendraría hijos de su misma índole, aunque sería posible que no siempre resultara así. Por eso, por orden del dios, los guardianes habrían de velar, como primera obligación, por que cada individuo, independientemente de su procedencia filial, ejerza efectivamente la función para la que su propia constitución lo ha dotado. El relato finaliza con una advertencia que enfatiza la gravedad de esta obligación y afirma que un oráculo ha previsto la destrucción del Estado en caso de que su cuidado quedara en manos de los hombres de hierro y de bronce.

Ante todo, lo que hay que constatar es si este relato está efectivamente vinculado al tercer caso de tò en toîs lógois pseûdos y si es uno de los relatos a los que se refiere Platón con ese caso de falsedad verbal. Pero no cabe guardar demasiadas dudas al respecto, pues Platón es muy claro al introducir referencias expresas a los pasajes previos, como he consignado antes. Platón también se refiere de manera explícita al relato como un mûthos que es pseûdos y cuyo contenido versa además sobre acontecimientos que, con toda propiedad, pueden calificarse de palaiá. En cambio, lo que no resulta tan claro es si, puesto que en este relato Platón ofrece un ejemplo del tercer caso de falsedad verbal, éste ofrece efectivamente algún apoyo a la tesis aquí sostenida o si, por el contrario, refuerza, más bien, la idea de que lo que Platón se propone en 382d1-3 es recurrir al uso de una "mentira".

El argumento más fuerte en favor de esto último es el hecho de que quienes narran el relato saben que lo que cuentan no ha sucedido así $\mathrm{y}$, a pesar de ello, incurren en la comunicación de esa falsedad: ni la tierra los ha engendrado, ni los ha provisto de toda la dotación que poseen, ni han nacido adultos, ni es cierto que lo que les han enseñado sean ilusiones oníricas. La disposición deliberada de persuadir a otros de algo que se sabe que no es cierto habla naturalmente en favor de la interpretación de que el relato sería, sin más, una mentira. En favor de esto se puede aducir, a su vez, que en el relato se combinan dos de los

${ }^{25}$ Versión del mito hesiódico de las edades, aunque con notables diferencias. Véase Hesíodo, Op. 106-201.

Diánoia, vol. LX, no. 74 (mayo de 2015). 
elementos que en $\mathrm{Hp}$. Mi. tipifican la mentira, a saber, (i) la conciencia de que lo que se cuenta en la narración no es así y (ii) la deliberación de comunicarlo. Invocar la nobleza del fin por el que se recurre a la difusión del mito, esto es, el fortalecimiento de los gobernantes en una convicción verdadera, no es argumento para aliviar la carga pragmática que compromete a este relato. A pesar de que su núcleo tipológico sea un contenido doxástico verdadero, si como medio para convencer de él se propala con el propósito de distorsión un cuento sobre cosas que es sabido no han tenido lugar de esa manera, estamos ante la instrumentalización de aquél por un interés político. Esto está muy lejos de la creación de relatos sobre acontecimientos antiguos que, ante la ignorancia de cómo pudieron haber sucedido, y a pesar de ello, los poetas procurarían componer para ofrecer una versión lo más semejante posible de la verdad.

Ahora bien, junto a la conciencia de que el mito narra cosas que no son ciertas y a la decisión de divulgarlo, hay que advertir también que la tipificación de la mentira involucra dos elementos más que no se cumplen en el caso del relato fenicio, a saber, (i) el relato narra algo de lo que no se tiene conocimiento, esto es, el hecho antiguo concerniente al origen mismo de los ciudadanos de un Estado; y (ii) por causa de ese desconocimiento resulta imposible componer al respecto una versión distorsionante del hecho, pues sólo es posible errar en el intento de asimilación a la verdad (382e1) cuando se inventa un cuento sobre aquello; dicho de otro modo, es imposible incurrir en una mentira al proferir ese relato si, como insiste Platón en $H p$. Mi., el punto de partida para su composición es la ignorancia insalvable sobre sucesos sumamente lejanos en el tiempo. Los poetas han creado una versión que ciertamente no puede ser verdadera en la medida en que ha sido ideada a partir de un inevitable desconocimiento de acontecimientos lejanos en el tiempo y, justamente en esa misma medida, sería incorrecto tomar esa versión por una mentira. ${ }^{26}$

En realidad, el problema que les plantea este relato a los participantes en el diálogo — como muestra el recelo de Sócrates a exponerlo (414 c8, e3) y el escepticismo sobre su capacidad persuasiva (414c8, 415c6) - reside no en el hecho de que responda a una voluntad latente

${ }^{26}$ No puedo aceptar, en cambio, la siguiente afirmación de Santa Cruz 2007, p. 284: "La mentira noble es mentira porque involucra deliberada no veracidad (414b8 y ss.)"; diría, más bien, que esta falsedad es tal porque involucra ausencia de conocimiento del modo efectivo en que sucedieron los hechos antiguos que dan apoyo histórico a la creencia de que los ciudadanos son iguales y, sin embargo, deben cumplir en el Estado funciones diferentes.

Diánoia, vol. LX, no. 74 (mayo de 2015). 
de engaño respecto al núcleo tipológico que transmite, sino más bien en su nivel narrativo, que no encauza esa verdad tipológica sino que, incluso, obstaculiza su comunicación. ${ }^{27}$ Pero, insisto, no estamos aquí ante la comunicación deliberada de una falsedad por parte de alguien que conoce la verdad correlativa a ella, esto es, ante una "mentira", sino frente a un cuento cuyo nivel literal no logra remitir a un significado bien determinable (y determinado en la discusión que le hace de marco).

Por último, y dando por sentado lo dicho sobre el relato fenicio, hay que añadir una indicación final. Lo que Sócrates propone es, en términos precisos, la creación de un relato de autoctonía al estilo del fenicio que menciona, ${ }^{28}$ y no necesariamente el empleo de la literalidad de esa narración; versión que acuñaron y difundieron los poetas y que Sócrates claramente desestimó. Él sólo la menciona como caso de un mito que ya existe, expresando con ocasión de él que sería deseable ${ }^{29}$ acuñar un material literario acorde a la creencia que anteriormente han establecido como verdadera. No es, por tanto, precisamente este relato fenicio lo que Platón propone como una falsedad noble, sino, en sentido estricto, un relato que ha de confeccionarse con base en las tipologías provistas para refrendar la convicción relativa al origen de la organización política. De modo que, incluso por esta vía, hay que descargar a Platón de haber justificado el uso de la mentira en contextos políticos mediante el empleo de los relatos literarios, y particularmente del relato fenicio.

${ }^{27}$ El problema que plantea, en concreto, este relato no es tanto el hecho de que sea más o menos palmariamente una mentira, sino, como puede percibirse en el recelo de Sócrates para contarlo, en el hecho de que no cumple suficientemente con la otra característica consignada en $382 \mathrm{~d} 1-3$, a saber, quienes han compuesto este relato han fallado en su intento de hacerlo aphomoioûntes, es decir, resulta tan poco verosímil que no proporciona firmeza a la convicción verdadera, sino que, más bien, se la resta. Que el problema de este relato es el de su escasa credibilidad se apoya también en $L g$. 663e6, donde se lo califica de apithanón.

${ }^{28}$ Que su propuesta sea acuñar otro relato del estilo puede verse en el valor condicional del participio pseudómenous junto a los pronombres indefinidos que se usan para referirse a ese relato por crear: gennaîon ti eán pseudómenous, es decir, "si compusiéramos una [de esas falsedades], alguna noble" (414b9), poîon ti: "ia una como cuál [te refieres]?" (414c3), phoinikikón ti: "a una como cierto relato fenicio" (414c4). Esto indica que no se está hablando aquí de acoger este relato tal cual, sino alguno como él.

${ }^{29} \mathrm{El}$ carácter desiderativo de la propuesta de Sócrates puede verse en el uso del optativo en la pregunta que da inicio a esta sección: àn [...] tôn pseudôn tôn en déonti gignoménon ("si compusiéramos [una de las falsedades]" 414b8). 


\section{Recapitulación}

He procurado mostrar puntualmente en el problemático pasaje de $R$. II $377 a 6$ el deslindamiento de niveles de sentido en relación con el término pseûdos aplicado al caso de los relatos literarios. A partir de este deslindamiento he defendido que no habría — como sostienen diversos intérpretes - contradicción alguna cuando Platón hace referencia al valor, al mismo tiempo negativo y positivo, de la falsedad literaria. La falsedad de los relatos literarios no debe entenderse como "mentira" o "ficción", sino más bien a la luz de su doble significación (fáctica/literal/mitológica, relativa al desconocimiento de la verdad sobre los hechos históricos que se narran, y normativa/tipológica/no literal, no concerniente a hechos históricos). Tal deslindamiento explica cuál es, para Platón, la dimensión de verdad comprometida en una narración literaria falsa y, en consecuencia, la específica legitimación de su empleo en materia pedagógico-política. En tal medida, el relato fenicio no implica, como se ha podido ver, una mentira, pues esa "falsedad noble" no involucra dos de los elementos esenciales de la mentira pautados por Platón en $H p$. Mi., a saber: el relato es comunicado, sí, con deliberación y conciencia de que narra cosas que no son ciertas, pero (i) lo hace sin el conocimiento de la verdad correlativa a lo que se falsifica, por lo cual (ii) es imposible que, al narrarlo, se incurra en la distorsión de ella. El cuento fenicio es así sólo un caso que se trae a colación con el objetivo de indicar una de las narraciones existentes del tipo de relato que sería deseable crear para dar cauce y fortalecer una convicción verdadera sobre la organización del Estado. En esta medida, creo, hay que restar la carga pragmática de la mentira que eventualmente podría llegar a comprometer a este relato.*

\section{BIBLIOGRAFÍA}

Ediciones de la República

Adam, J. (ed.), 1969, The Republic of Plato, introd. D.A. Rees, Cambridge University Press, Cambridge (1a. ed. 1902).

Burnet, J., 1900-1907, Platonis opera, recognovit brevique adnotatione critica instruxit Ioannes Burnet, vols. I-V, Clarendon Press, Oxford.

Cornford, F.M. (ed.), 1961, The Republic of Plato, Clarendon Press, Oxford.

* Deseo expresar mi agradecimiento al árbitro de Diánoia que objetó mi primera versión de la sección 5; su observación me ayudó mucho a revisar y reforzar, en la medida de mis posibilidades, el hilo argumentativo en favor de la tesis propuesta allí. 
Platón, 1986, Diálogos, vol. IV: República, trad. y notas C. Eggers Lan, Gredos, Madrid.

Veggetti, M., 1998, Platone. La Repubblica. Traduzione e commento, vol. II, Bibliopolis, Nápoles.

Bibliografía secundaria

Annas, J., 1982, "Plato on the Triviality of Literature", en J. Moravcsik y P. Temko (comps.), Plato on Beauty, Wisdom and the Arts, Rowman and Littlefield, Nueva Jersey, pp. 1-28; reimpr. en N.D. Smith (comp.),

— , 1981, An Introduction to Plato's Republic, Clarendon Press, Oxford Plato: Critical Assessments, Londres, Routledge, 1998, vol. 3, pp. 273-295.

Ashbaugh, A.F., 1991, "La verdad de la ficción (Una lectura de República 376e5377a6)", Revista Latinoamericana de Filosofía, vol. 17, no. 2, pp. 307-319.

Ast, F., 1836, Lexicon platonicum sive vocum platonicarum index, Weidmann, Leipzig; reimpr. en Rudolf Habelt, Bonn, 1956, vols. II-III.

Battin, M.P., 1977, "Plato on True and False Poetry", The Journal of Aesthetics and Art Criticism, vol. 36, no. 2, pp. 163-174.

Belfiore, E., 1985, "Lies Unlike the Truth': Plato on Hesiod, Theogony 27", Transactions of the American Philological Association, vol. 115, pp. 47-57.

Bordt, M., 2006, Platons Theologie, Karl Alber, Friburgo/Múnich.

Chantraîne, P., 1968, Dictionnaire étymologique de la langue grecque. Histoire des mots, Klincksiec, París.

Calabi, F., 1998, "La nobile menzogna”, en Veggetti 1998, pp. 445-457.

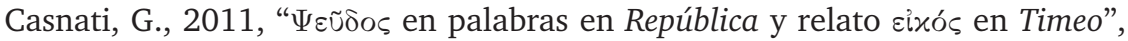
Nova Tellus, vol. 29, no. 2, pp. 47-85.

Crossman, R., 1963, Plato Today, Allen and Unwin, Londres.

Ferrari, F., 2008, "Plato and Poetry", en G.A. Kennedy (comp.), The Cambridge History of Literary Criticism, vol. 1: Classical Criticism, Cambridge University Press, Cambridge, pp. 92-148.

__, 1998, "Theologia”, en Veggetti 1998, pp. 402-425.

Flashar, H., 1958, Der Dialog Ion als Zeugnis platonischer Philosophie, AkademieVerlag, Berlín.

Gastaldi, S., 1998, "Paideia/mythologia", en Veggetti 1998, pp. 333-392. Gill, C., 1993, "Plato on Falsehood-Not Fiction", en C. Gill y T.P. Wiseman (comps.), Lies and Fiction in the Ancient World, University of Texas Press, Austin, pp. 38-87.

Halliwell, S., 2000, “The Subjection of Mythos to Logos: Plato's Citations of Poets", The Classical Quarterly, vol. 50, no. 1, pp. 94-112.

Liddell, H.G., R. Scott y H.S. Jones, 1996, Greek-English Lexicon, Clarendon Press, Oxford.

Notomi, N., 2011, "Image-Making in Republic X and the Sophist", en P. Destrée y F.-G. Herrmann (comps.), Plato and the Poets, Brill, Leiden/Boston, pp. 299304.

Diánoia, vol. LX, no. 74 (mayo de 2015). 
Popper, K., 1957, La sociedad abierta y sus enemigos, trad. E. Loedel, Paidós, Buenos Aires.

Santa Cruz, M.I., 2007, "Falsedad genuina y falsedad verbal en Platón", en A.M. González de Tobia (comp.), Lenguaje, discurso y civilización. De Grecia a la Modernidad, Universidad Nacional de La Plata-Facultad de Filosofía y Humanidades, La Plata, pp. 271-286.

Schofield, M., 2006, Plato: Political Philosophy, Oxford University Press, Oxford/Nueva York.

Tate, J., 1929, "Plato and 'Imitation'”, The Classical Quarterly, vol. 26, nos. 3-4, pp. 161-169.

Vernant, J.-P., 1973, Mito y pensamiento en la Grecia antigua, trad. J.D. López Bonillo, Ariel, Barcelona.

Recibido el 16 de septiembre de 2014; aceptado el 5 de febrero de 2015. 